\title{
Dispepsi Şikâyeti ile Başvuran Hastalarda Helikobakter Pilori Pozitifliği Açısından C-14 Üre Nefes Testi ile Endoskopinin Karşılaştırılması
}

\author{
Comparison of Endoscopy and C-14 Urea Breath Test in Terms of Helicobacter Pylori Positivity in \\ Patients Admitted with Complaints of Dyspepsia
}

\author{
Yasemin Korkut ${ }^{1}$, Türkan Kilit ${ }^{2}$, Ilknur Işık ${ }^{3}$, Celal Kilit ${ }^{4}$ \\ ${ }^{1}$ Aile Hekimliği Ana Bilim Dalı, Tıp Fakültesi, Dumlupınar Üniversitesi, Kütahya, Türkiye \\ ${ }^{2}$ İç Hastalıkları Ana Bilim Dalı, Tıp Fakültesi, Dumlupınar Üniversitesi, Kütahya, Türkiye \\ ${ }^{3}$ Nükleer Tıp Ana Bilim Dalı, Tıp Fakültesi, Dumlupınar Üniversitesi, Kütahya, Türkiye \\ ${ }^{4}$ Kardiyoloji Ana Bilim Dalı, Tıp Fakültesi, Dumlupınar Üniversitesi, Kütahya, Türkiye
}

\section{ÖZET}

Giriş: Bu çalışmada, Helikobakter Pilori (HP) tanısında Karbon-14 Üre Nefes Testini (C-14 ÜNT) endoskopi ile karşılaştırmayı ve takipte C-14 ÜNT'nin kullanılabilirliğini göstermeyi amaçladık.

Yöntem: Çalışmaya Nisan 2012-Şubat 2015 tarihleri arasında Dumlupınar Üniversitesi Tıp Fakültesi Kütahya Evliya Çelebi Eğitim ve Araştırma Hastanesine dispeptik şikayetlerle başvuran ve HP enfeksiyonu şüphesi ile C-14 ÜNT yapılan 183 hasta dahil edildi. Hastaların kayıtları geriye dönük olarak incelendi.

Bulgular: Çalışmaya yaş aralığı 7-71 arasında değişen 183 hasta alındı. Yaş ortalaması $31 \pm 15$ yıl idi ve hastaların 129'u kadın (\%7), 54'ü erkekti (\%30). C-14 ÜNT sonucunda hastaların 77'sinde (\%42) HP negatif, 2'sinde (\%1) HP şüpheli, 104 hastada (\%57) HP pozitifti. HP negatif ve HP pozitif gruplar arasında yaş ve cinsiyet bakımından anlamlı fark yoktu. C-14 ÜNT ile üst gastrointestinal sistem endoskopi sonuçları karşılaştırıldığında, iki yöntem arasında HP pozitifliğinin tespiti açısından fark olmadığı tespit edildi ( $>0.05$ ).

Sonuç: C-14 ÜNT, HP tanısında kullanılabilecek güvenilir, noninvaziv ve pratik bir testtir.

Anahtar kelimeler: Dispepsi, Endoskopi, Gastrointestinal, Helikobakter Pilori, Nefes Testleri

\begin{abstract}
Introduction: In this study, we aimed to compare Carbon-14 Urea Breath Test (C-14 UBT) and endoscopy in diagnosis of Helicobacter pylori (HP) and show the availability of the C-14 UBT in follow-up.

Methods: We enrolled 183 patients who were admitted to Dumlupınar University Faculty of Medicine, Kütahya Evliya Çelebi Education and Research Hospital between April 2012-February 2015 with dyspeptic complaints and C-14 UBT performed due to the suspicion of HP infection. Patient records were analyzed retrospectively.

Results: We enrolled 183 patients with age range 7-71 years. The mean age was $31 \pm 15$ years and 129 of patients were female (7\%), and 54 were male $(30 \%)$. According to the results of C-14 UBT, HP was negative in 77 of patients (42\%), HP was probable in 2 of patients (1\%) and HP was positive in 104 patients (57\%). There was no significant difference between HP positive and HP negative groups in terms of age and gender. When compared the results of C-14 UBT with upper gastrointestinal system endoscopy, it was found that there was no difference between the two methods for the determination of the HP positivity $(\mathrm{p}>0.05)$.

Conclusion: C-14 UBT is a reliable, noninvasive and practical test which can be used in the diagnosis of HP.

Keywords: Dyspepsia, Endoscopy, Gastrointestinal, Helicobacter Pylori, Breath Tests
\end{abstract}

Başvuru / Submission: Şubat / February 29, 2016

Kabul / Acceptance: Nisan / April 4, 2016

Yazışma / Correspondence: Dr Yasemin Korkut, Dumlupınar Üniversitesi, Tıp Fakültesi, Aile Hekimliği Ana Bilim Dalı, 43100 Kütahya, Türkiye

E-mail: ykorkut95@hotmail.com

Atıf / Cite: Korkut Y, Kilit T, Işık İ, Kilit C. Dispepsi şikâyeti ile başvuran hastalarda Helikobakter Pilori pozitifliği açısından C-14 Üre Nefes Testi ile endoskopinin karşılaştırılması. Fam Pract Palliat Care. 2016;1(1):9-12 


\section{GíRiș}

Dispepsi, toplumumuzda ve sağlı kuruluşlarına başvuran hastalarda sik rastlanan bir şikâyettir. Hasta tarafindan tanımlanması da, hekim tarafından anlaşılması da güç bir semptom olmasına rağmen toplumda y1llık prevalansı tespit edilebildiği kadarıyla \%25'dir ve tüm birinci basamak muayenelerinin ortalama \%2 ila 5 'ini oluşturur. Dispepsi tanı ve tedavisinde her birinin avantaj ve dezavantajları olan faklı yöntemler kullanılır. Dispepsi şikayetine neden olan önemli bir etken Helikobakter pilori (HP) enfeksiyonudur.

HP tüm dünyada yaygın olarak gözlenen, dünya nüfusunun önemli bir kısmını genellikle erken yaşlardan itibaren enfekte eden, spiral şekilli, gram (-), hareketli bir mikroorganizmadır (1). HP günümüzde tüm gastrointestinal hastalıklarda en çok suçlanan bakteridir (2).

Duodenal ülserli hastaların \% 90'1nda ve peptik ülserli hastaların \% 60-70'inde etkendir. Gastrit ve peptik ülserli hastalarda tedaviyi yönlendirmede etyolojinin tespiti ve tedavi sonrası eradikasyon sağlanıp sağlanmadığının değerlendirilmesi önem taşımaktadair $(1,3,4)$.

HP enfeksiyonu tanısı invaziv (endoskopi ve biyopsi) ya da noninvaziv tekniklerle (seroloji, üre nefes testi ya da dışkıda HP antijeninin saptanması v. b.) konabilir. Birinci basamak hekimlerinin de katkıda bulundukları 2005 Maastrich III. Konsensus Raporu, üre nefes testinin tanıda ve eradikasyonun etkinliğini değerlendirmede kullanılabileceğini, pratik olduğunu, doğruluğunun \%95'in üzerinde olduğunu bildirmiştir. Rapor, üre testini HP prevalansının \%20'yi aştığg toplumlar için önermektedir $(5,6)$.

Üre nefes testi HP'nin salgıladığı üreaz enziminin üreyi $\mathrm{CO} 2$ ve amonyağa parçalamasına dayanır. Hasta radyoaktif C14 işaretli üre kapsüllerini içer, midede kolonize olan HP üreyi parçalar. Ortaya çıkan CO2 dolaşıma karışır ve solunan hava ile dışarı atılır. Hastanın üflediği kartuş analizörde incelenerek HP araştırılır (7).

Çalışmamızın amacı, HP enfeksiyonundan şüphelenilen ve C-14 üre nefes testi (ÜNT) yapılan hastalar ile üst gastrointestinal sistem endoskopisi yapılan hastalar arasındaki HP pozitifliğinin değerlendirilmesi ve tedavi verilen hastalardaki tedavi sonrasi kontrol verilerinin karşılaştırılmasıdır. Dispepsisi olan ve HP pozitifliğinden şüphelenilen hastalara uygulanan, diğer testlere göre daha kolay uygulanması ve noninvaziv olmasından dolayı tanı ve tedavi sonrası eradikasyonun değerlendirilmesinde ve takipte yalnız başına C-14 ÜNT kullanılabilirliğinin gösterilmesidir.

\section{YÖNTEM}

Nisan 2012-Şubat 2015 tarihleri arasında Dumlupınar Üniversitesi Tıp Fakültesi Kütahya Evliya Çelebi Eğitim ve Araştırma Hastanesine yanma, karın ağrısı, bulantı gibi dispeptik şikayetlerle başvuran, HP enfeksiyonundan şüphelenilen 183 hastanın retrospektif olarak dosya kayıtları incelenerek uygun hastalar çalışmaya dahil edildi. Demografik özellikleri, şikâyetlerinin süresi, niteliği, önceki ilaç kullanımı öyküsü ile ilgili bilgiler dosyalarından edinildi.

C-14 testinin uygulanabilmesi için yeterli koopererasyonu olan hastalarda uygulanan C-14 ÜNT hastanemizde yapıldı. C14 ÜNT yapılmadan önce hastaların Bizmut içerikli ilaçlar ve HP eradikasyonunda kullanılan antibiyotikler için son bir ay, sukralfat ve proton pompa inhibitörleri için son iki hafta, antiasitler ve $\mathrm{H} 2$ reseptör blokerleri için son 1-2 gün, HP eradikasyonu dışındaki nedenlerle kullanılan antibiyotikler için son bir hafta olmak üzere belirtilen süreler içinde bu ilaçları kullanmamış olmak ve testin yapılacağı gün gece yarısından itibaren aç kalmış olmaları sağlanmış olan hastalardı.

C-14 ÜNT yapılan hastaların bir bölümüne de üst gastrointestinal endoskopisi hastanemizdeki Fujinon EG590WR marka cihaz kullanılarak yapılmış ve biyopsileri Sydney siniflamasina göre duodenum, antrum, corpustan alınmış olan hastalardı.

C-14 ÜNT yapılmış olan hastalar ile üst gis endoskopisi yapılan hastalar HP pozitifliği yönünden karşılaştırılarak kolay uygulanabilen, maliyeti az bir tetkik olan C-14 ÜNT'nin tanı için uygulanabilirliği ölçülmesi hedeflendi.

Çalışmada, istatistiksel analiz için SPSS 16.0 istatistik paket programı kullanıldı. Verilerin değerlendirilmesinde sayı, yüzde, ortalama ve standart sapma kullanıldı. Ölçümle belirtilen parametrik verilerin bağımsız gruplar arası karşılaştırmalarında Student t-testi kullanıldı. Kategorik verilerin gruplar arası karşılaştırmalarında ki-kare testi, bağımlı gruplardaki karşılaştırmalarında ise McNemar testi kullanıldı. HP pozitifliği açısından üst gastrointestinal sistem endoskopisi ile C-14 ÜNT sonuçlarının uyumunu değerlendirmek için Kappa analizi kullanıldı. Bütün analizlerde $\mathrm{p}$ değerinin $<0,05$ olması istatistiksel olarak anlamlı kabul edildi.

Dispeptik yakınmaları olan ve herhangi bir nedenle antibiyotik kullanmayan olgularda üst gastrointestinal sistem endoskopisi ile C-14 üre nefes testinin tanı koymadaki oranları araştırıldı. Endoskopi sonrası da biyopsi örnekleri histopatolojik olarak incelendi. Çalışmaya alınan olgulara gerek klinik bulguları gerekse endoskopik ve histopatolojik sonuçlarına göre uygun dozlarda Lansoprozol, Amoksisilin ve Klaritromisinden oluşan üçlü tedavi protokolü uygulanmıştı. Tedavi sonrasıkontrol endoskopisi uygulanmış olan hastaların dosyaları tarand 1 . klinik muayeneleri, üre nefes testi ve hastaların bir kısmında da endoskopi ile tedavi yanıtları dosyalardan araştırıldı.

\section{BULGULAR}

Başlangıçta 199 olan hasta sayısı 16 hastanın uygun kriterleri doldurmaması nedeniyle çalışmadan çıkarılması sonucunda 183 hasta ile sonlandırıldı. Çalışmaya dahil edilen hastaların yaş aralığı 7-71 arasında değişirken, yaş ortalaması $31 \pm 15$ idi. Hastaların 129’u kadın (\%7), 54’ü erkekti (\%30). C-14 ÜNT sonucunda hastaların 77'sinde (\%42) HP negatif, 2 'sinde (\%1) HP şüpheli, 104 hastada (\%57) HP pozitifti. HP negatif ve HP pozitif gruplar arasında yaş ve cinsiyet bakımından anlamlı fark yoktu (Tablo 1). 
Tablo 1. Üre nefes testi sonucunda HP pozitif olan hastaların demografik özelliklerinin karşılaştırılması

\begin{tabular}{llll}
\hline \multicolumn{1}{c}{ Değişken } & $\begin{array}{l}\text { HP negatif } \\
(\mathrm{n}=77)\end{array}$ & $\begin{array}{l}\text { HP pozitif } \\
(\mathrm{n}=104)\end{array}$ & $\mathrm{p}$ \\
\hline Yaş (y1l) & $28,8 \pm 15,0$ & $31,0 \pm 14,1$ & 0,17 \\
Cinsiyet [(erkek, \%)] & $23(42,6)$ & $30(55,6)$ & 0,81 \\
Sigara kullanan & 29 & 42 & 0,36 \\
Alkol kullanan & 14 & 11 & 0,78 \\
\hline
\end{tabular}

Endoskopi yapılmasını kabul etmiş olan hastaların 41'ine $(\% 22,4)$ üst gastrointestinal sistem endoskopisi yapılarak 22 'sinde $(\% 53,7)$ HP pozitif saptanmıştı.

Endoskopi sonucuna göre C-14 ÜNT pozitif olan hastaların oranı Figür 1'de gösterilmiştir. Hastaların 23'üne $(\% 12,6)$ tedavi sonrası kontrol C-14 ÜNT tekrarlanmış ve 10 hastada (\%43) HP pozitif, 13’ünde (\%57) HP negatifti.

Figür 1: Endoskopi sonucuna göre HP pozitif ve negatif olan hastalarda $C-14$ üre nefes testine göre HP pozitif ve negatif hasta yüzdeleri.

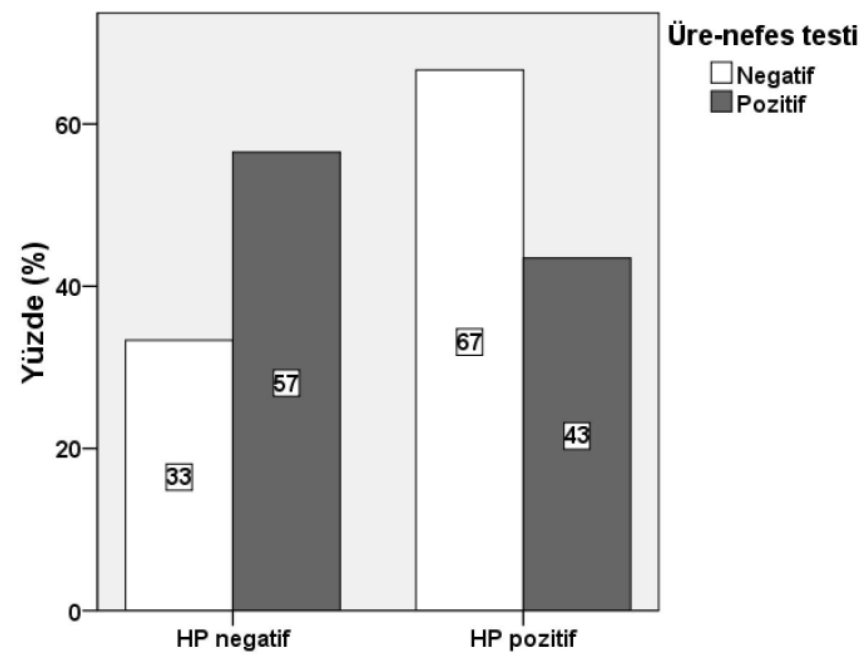

C-14 ÜNT ile aynı zamanda üst gastrointestinal sistem endoskopisi yapılan hastalar karşılaştırıldığında her iki yöntem arasında HP pozitifliğinin tespiti açısından fark olmadığ 1 tespit edildi $(\mathrm{p}>0.05)$.

İki yöntem arasındaki uyum zayıftı (kappa=-0.023) ve istatistiksel olarak anlamsızdı $(\mathrm{p}=0.14)$ (Tablo 2).
Tablo 2. C-14 Üre nefes testi ile endoskopinin (HP sonuçlarının) karşılaștırııması.

\begin{tabular}{lllll}
\hline & & \multicolumn{3}{c}{ Endoskopi } \\
& & Negatif & Pozitif & Toplam \\
\hline \multirow{3}{*}{ C-14 ÜNT } & Pegatif & 6 & 12 & 18 \\
& Pozitif & 13 & 10 & 23 \\
& Toplam & 19 & 22 & 41 \\
\hline
\end{tabular}

Tedavinin etkinliğini C-14 ÜNT ile değerlendirdiğimizde istatistiksel yönden anlamlı sonuçlar alındı $(p=0.001)$ fakat endoskopi ile karşılaştırılmasında hasta sayısı yeterli değildi ve makaledeki primer amacımız ilk tanıdaki etkinliklerin karşılaştırılmasıydı.

\section{TARTIŞMA}

Helikobakter pilori, dünyadaki en yaygın enfeksiyöz etkenlerden biridir. Dünya nüfusunun yaklaşık \%50'sini etkilediği düşünülmektedir. Kalabalık yaşam, kötü hijyen koşulları ve düşük sosyoekonomik koşullar infeksiyon oranını arttırmaktadır (8-10).

HP, gastrit, gastrik ve duodenal ülser, gastrik mukoza ilişkili lenfoma (MALT lenfoma) ve gastrik adenokanser etyolojisinde önemli bir etken olduğu için tanı konularak tedaviye başlanması önemlidir (11-16). International Agency for Cancer Research'a göre de HP karsinojen bir mikroorganizma olarak kabul edilmiştir $(1,17)$.

Ayrıca son dönemde yapılan araştırmalar sonucunda HP enfeksiyonunun, hematolojik, nörolojik ve kardiyovasküler hastalıklar gibi gastrointestinal sistem dışı hastalıklarla da ilişkisi olduğu tespit görülmüştür (18).

Aile hekimliği poliklinikleri başta olmak üzere, HP'ye sekonder olarak gelişen dispeptik yakınmalarla doktora başvuran hastaların oranı oldukça fazladır.

$\mathrm{Bu}$ açıdan bakıldığında hastalara özel uzmanlık gerektiren endoskopi gibi invaziv bir işlem yapılmasındansa daha kolay, ucuz, noninvaziv bir yöntem olarak C-14 ÜNT'nin yapılması HP tespiti açısından ön plana çıkmaktadır $(19,20)$.

Çalışmamızda dispeptik hastalarda C-14 ÜNT ile HP sıklığı \%57 oranında bulundu. Türkiye'de erişkin popülasyonda HP sıklığı üre nefes testi ile araştıran TURHEP (Helicobacter Pylori Prevalans Araştırması) çalışmasında ise oran \%82 idi (21).

Türkölmez ve ark. Ankara'da gastrik yakınmalar nedeniyle C-14 ÜNT istenen 1567 hastada HP sıklığını \%68 bulmuşlardır (22).

Çalışmamızda saptanan HP sıklığı ülkemizdeki prevalans çalışmalarından daha düşüktür. Ancak hastanedeki çalışmalarının sonuçları ile benzerlik göstermektedir $(21,22)$. 
Polikliniğimizde belirlenen HP sıklığının daha düşük olması, hastanemizin il merkezinde olması sebebiyle kırsal kesime göre başvuran hastalarımızın sosyoekonomik durumlarının daha iyi olması ile açıklanabilir.

Çalışmamızda HP enfeksiyonu ile cinsiyet arasında anlamlı ilişki bulunmadı. Dispeptik hastalarda HP sıklığının araştırıldığı farklı çalışmalarda da cinsiyetle HP sıklığı arasında anlamlı ilişki yoktu. Türkölmez ve ark.'nın çalışmasında cinsiyetle HP enfeksiyonu arasında istatistiksel bir ilişki bulunmadi (22).

Genel popülasyonda, HP sıklığının kadın ve erkeklerde eşit olduğunu gösteren çalışmaların yanında, erkek cinsiyetin risk oluşturduğunu ileri süren epidemiyolojik çalışmalar da bulunmaktadır (23). Ancak biz cinsiyet bakımından anlamlı bir farka rastlamadik.

Çalışmamızda, C-14 ÜNT'nin noninvaziv olması, kolay uygulanabilmesi ve doğru tanı koyma potansiyelinin yüksek olması göz önünde bulundurularak özellikle üst gastrointestinal sistem endoskopisinin yapılamadığı durumlar başta olmak üzere özellikle aile hekimliği polikliniklerinde uygulanabileceğini göstermek istedik.

Hasta sayısının çok fazla olmaması, C-14 ÜNT yapılan hastaların hepsine endoskopisinin yapılamaması çalışmanın kısıtlılıklarındandır.

\section{Çıkar çatışması: Bildirilmedi.}

Finansal destek: Bildirilmedi.

\section{KAYNAKLAR}

1. Dunn B E, Cohen H, Blaser M J. Helicobacter pylori. Clinical microbiology Reviews.1997; 720-741.

2. European Helicobacter pylori Study Group. Current European concepts in the management of Helicobacter pylori infection. The Maastricht consensus report. Gut. 1997;(41):8- 13.

3. Dooley CP. Background and historical considerations of Helicobacter pylori. Gastroenterology Clin. North Am. 1993;22(1):1-19.

4. National Institutes of Health Consensus Development Conference Statement 1994;(2):7-9.

5. Malfertheiner P, Megraud F, O'Morain C ve ark. Current concepts in the management of Helicobacter pylori infection. The Maastrich III Consensus Report. Gut 2007; 56:772-81.

6. Erdoğan AF, Turan İ, Gereklioğlu Ç ve ark. Aile hekimliği polikliniğinde dispeptik hastalarda Helicobacter pylori sıklığı. Türk Aile Hek Derg 2008;12(4):198-202.

7. Balon H, Gold CA, Dworkin HJ, McCormick VA, Freitas JE. Procedure guideline for carbon-14-urea breath test. The Journal of Nuclear Medicine 1998;39:2012-14.

8. Everhart J E. Recent developments in the epidemiology of Helicobacter pylori. Gastroenterology Clinics of North America. 2000;29(3):559-578.

9. Altındiş M, Özdemir M. Helicobacter Pylori ve Tanısı. Kocatepe Tip Dergisi. 2003;2:1-12.

10. Selçukcan Aydın F, Demirkıran Urgancı N, Üzüm Yenici F. Pediatrik Yaş Grubunda Helikobakter Pilori Kaynaklı
Gastrit Tanısında Kullanılan Yöntemlerin Karşılaştırılması Ve Tedavi Sonrası Takipte Noninvaziv Bir Test Olarak Üre Nefes Testinin Kullanılabilirliği. Düzce Tıp Dergisi 2011;13(1):6-14.

11. Altıntaş E, Ulu O, Sezgin O, Aydin O, Camdeviren H. Comparison of ranitidine, bismuth citrate, tetracycline and metronidazole with ranitidine, bismuth citrate and azithromycin for the eradication of Helicobacter pylori in patients resistant to PPI based triple therapy. Turk J Gastroenterol 2004; 15:90-93.

12. Köksal AS, Önder FO, Torun S, Parlak E, Sayılır A, Tayfur $\mathrm{O}$, et al. Twice a day quadruple therapy for the first-line treatment of Helicobacter pylori in an area with a high prevalence of background antibiotic resistance. Acta Gastroenterol Belg 2013;76:34-37.

13. Wong WM, Gu Q, Lam SK, Fung FM, Lai KC, Hu WH, et al. Randomized controlled study of rabeprazole, levofloxacin and rifabutin triple therapy vs. quadruple therapy as second-line treatment for Helicobacter pylori infection. Aliment Pharmacol Ther 2003;17:553-560.

14. Zheng Q, Chen WJ, Lu H, Sun QJ, Xiao SD. Comparison of the efficacy of triple versus quadruple therapy on the eradication of Helicobacter pylori and antibiotic resistance. J Dig Dis 2010;11:313-318.

15. Frenck RW Jr, Clemens J. Helicobacter in the developing world. Microbes Infect 2003;5:705-713.

16. Özbalcı G, Yürüker S, Tarım İ ve ark. Helikobakter pilori eradikasyonunda birinci basamak tedavi: bir cerrahi kliniğinin deneyimleri. Ulusal Cer Derg 2014;30:133-7.

17. Bingöl R. Helicobacter pylori Mikrobiyolojisi. 9. Türk Klinik ve Mikrobiyoloji İnfeksiyon Hastalıkları Kongresi, 3-8 Ekim, Antalya; Kongre Kitab1. 1999;51-55.

18. Georgopoulos SD, Papastergiou V, Karatapanis S. Current options for the treatment of Helicobacter pylori. Expert Opin Pharmacother 2013;14:211-223.

19. Mégraud F, Lehours P. Helicobacter pylori Detection and Antimicrobial Susceptibility Testing Clin Microbiol Rev. 2007;20(2):280-322.

20. Köksal AŞ, Oğuz D, Özden A. Türkiye'de birinci basamak sağlık kurumlarına başvuran hastalarda dispepsi görülme sıklığı. Akademik Gastroenteroloji Dergisi 2008;7(1):1117.

21. Özaydın ANG. Türkiye'de Helicobacter pylori prevalans çalışması sonucu TURHEP çalışması. Panel II. HepatoGastroenteroloji Kongresi 2005.

22. Türkölmez S, Cayır D, Aydoğan F, Korkmaz M. The relationship of Helicobacter pylori positivity with age, sex, and $\mathrm{ABO} /$ rhesus blood groups in patients with gastrointestinal complaints in Turkey. Helicobacter 2007;12:244-50.

23. Duynhoven YTH, de Jonge R. Transmission of helicobacter pylori: A role for food? Bulletin of the World Health Organization 2001;79:455-60. 